\title{
ПОРЯДОК РАССМОТРЕНИЯ ДЕЛ ОБ АДМИНИСТРАТИВНОМ ПРАВОНАРУШЕНИИ ПРИ ОСУЩЕСТВЛЕНИИ ВЕДОМСТВЕННОГО КОНТРОЛЯ В СФЕРЕ ГОСУДАРСТВЕННОГО ОБОРОННОГО ЗАКАЗА
}

Аннотация. Предметом исследования является порядок рассмотрения дел об административном правонарушении при осуществлении ведомственного контроля в срере государственного оборонного заказа (ГОз), вопросы административной ответственности. Административной ответственностью в области государственного оборонного заказа является применение судьями и специально уполномоченными должностными лицами федеральных органов исполнительной власти административных наказаний к физическим и юридическим лицам за совершение административных правонарушений в области ГОЗ, предусмотренных КоАП РФ в сорере ГОЗ. В соответствии с Федеральным законом от 05.04.2013 N 44-Ф3 «О контрактной системе в сфере закупок товаров, работ, услуг для обеспечения государственных и муниципальных нужд» (далее 44-Ф3) согласно статье 3 определяются основные понятия, используемые в срере осуществления контроля в отношении контрактов в сфере государственного оборонного заказа. В частности, понятие «контрольный орган в сфере закупок означает "...федеральный орган исполнительной власти, орган исполнительной власти субъекта Российской Федерации, орган местного самоуправления муниципального района, орган местного самоуправления городского округа, уполномоченные на осуществление контроля в сфере закупок, а также федеральный орган исполнительной власти, уполномоченный на осуществление функций по контролю (надзору) в сфере государственного оборонного заказа (далее ГОз) и в сфере закупок товаров, работ, услуг для обеспечения федеральных нужд, которые не относятся к государственному оборонному заказу и сведения о которых составляют государственную тайну". Функция надзора заключается в постоянном, систематическом наблюдении специальных государственных органов за деятельностью не подчиненных им органов или лиц с целью выявления нарушений законности. Предметом регулирования ведомственного контроля является проверка соблюдения законодательства Российской Федерации в сфере государственного оборонного заказа государственными заказчиками, головными исполнителями, исполнителями, федеральными органами исполнительной власти, иными осуществляющими в установленном порядке функции указанных органов органами или организациями, а также их должностными лицами. Контролирующий орган при выявлении признаков нарушения Федерального закона "О государственном оборонном заказе» № 275-ФЗ возбуждает и рассматривает дела о нарушении законодательства в срере государственного оборонного заказа. Возбуждение дела об административном правонарушении осуществляется в общем порядке, установленном законодательством Российской Федерации Методологической базой исследования является диалектический материализм и основанная на нем система общенаучных и частнонаучных методов, в том числе: формально-логчческий метод, системный метод, метод сравнительного правоведения и др. В статье рассматриваются вопросы административно-правового регулирования порядка рассмотрения дел об административном правонарушении при осуществлении ведомственного контроля в сфере государственного оборонного заказа. Проанализированы особенности процедур рассмотрения дел об административных правонарушениях в срере государственного оборонного заказа (ГОЗ), а также вопросы, связанные с осуществления ведомственного контроля. Приведено определение административной ответственности в области государственного оборонного заказа как применение судьями и специально уполномоченными должностными лицами федеральных органов исполнительной власти административных наказаний к физическим и юридическим лицам за совершение административ- 
ных правонарушений в области ГОЗ, предусмотренных КоАП РФ, содержания ведомственного контроля и понятия контролирующий орган.

Ключевые слова: комиссия, органы исполнительной власти, муниципальные нужды, административная отвественность, КоАП РФ, надзор, предписание, срок, закупки, возбуждение дела.

Abstract. The research subject is the procedure of consideration of cases on administrative offences during the departmental control in the sphere of government defence order (GDO) and the issues of administrative responsibility. The administrative responsibility in the sphere of GDO consists in the imposition of administrative punishment by judges and specially authorized federal executives on private individuals and corporate entities for administrative offences in the sphere of GDO provided by the Administrative Offences Code. The Federal Law of 05.04.2013 No 44 "On the contract based system of state procurement of goods, services and works", article 3, defines the main concepts used in the sphere of government defence order. Particularly, the concept of "supervisory body in the sphere of state procurement" means the federal executive body, municipal local authority, local authority of a city district, authorized to carry out supervision over procurement, and the federal executive body authorized to carry out supervisory functions in the sphere of government defence order and state procurement of goods, services and works which are not connected with the government defence order and the information about which is classified". The supervision function consists in the constant regular supervision of special government bodies over the work of bodies and persons, not subordinate to them, for the purpose of detecting legality infringements. The subject of regulation of departmental control is the inspection of observance of the legislation in the sphere of GDO by public procurement authorities, leading executives, executives, federal executive bodies and other entities and officials endowed with such powers. In case of detection of the signs of violation of the Federal Law "On government defence order" No 275, the supervisory authority initiates and considers the cases on the infringement of the legislation in the sphere of GDO. The proceedings are initiated according to the standard procedure established by the legislation of the Russian Federation. The research methodology is based on dialectical materialism and the set of general and special research methods, including the formal-logical, system, the method of comparative jurisprudence, etc. The article considers the issues of administrative regulation of the procedure of consideration of administrative cases in the sphere of government defence order. The author analyzes the peculiarities of consideration of such cases and the issues of departmental control. The author offers the definition of administrative responsibility in the sphere of government defence order as the imposition of administrative punishment by judges and specially authorized federal executives on private individuals and corporate entities for administrative offences in the sphere of GDO provided by the Administrative Offences Code, the concepts of departmental control and supervisory body.

Key words: initiation of proceedings, procurement, term, direction, supervision, commission, executive bodies, municipal needs, administrative responsibility, Administrative Offences Code.

$\mathrm{B}$ Кодексе об административных правонарушениях РФ (далее КоАП РФ) сформулированы основные определения, касающиеся административного правонарушения и административной ответственности, административного наказания и видов административных наказаний, а также производства по делам об административных правонарушениях. В нем содержится ряд норм, предусматривающих ответственность юридических, должностных и физических лиц за нарушения в сфере размещения и исполнения государственного оборонного заказа (далее ГОЗ).

Административной ответственностью в области государственного оборонного заказа является применение судьями и специально уполномоченными должностными лицами федеральных органов исполнительной власти административных наказаний к физическим и юридическим лицам за совершение административных правонарушений в области ГО3, предусмотренных КоАП РФ[1].

Исходя из совокупности признаков, можно выделить следующее определяющие признаки административного правонарушения в области госу- дарственного оборонного заказа: противоправное, общественно-опасное, виновное деяние должностного или юридического лица в сфере размещения и исполнения государственного оборонного заказа, за которое КоАП РФ установлена административная ответственность.

Административные правонарушения ГОЗ преимущественно содержатся в гл. 7 (ст. ст. 7.29 - 7.32) и гл. 19 (19.5 и 19.7) КоАП РФ.

В соответствии со статьей 15 Федерального закона от 29.12.2012 N 275-Ф3 «О государственном оборонном заказе» (далее №275-ФЗ) лица, виновные в нарушении норм указанного Федерального закона, других федеральных законов и иных нормативных правовых актов Российской Федерации в сфере государственного оборонного заказа, несут дисциплинарную, гражданско-правовую, административную и уголовную ответственность в соответствии с законодательством Российской Федерации. Кроме того, следует отметить, что к административной ответственности за одно и то же правонарушение могут быть привлечены одновременно должностное лицо заказчика и сам 


\section{Административное и муниципальное право 9 (105) • 2016}

заказчик - юридическое лицо. Согласно ч.3 ст.2.1 КоАП РФ назначение административного наказания юридическому лицу не освобождает от административной ответственности за данное правонарушение виновное физическое лицо, равно как и привлечение к административной или уголовной ответственности физического лица не освобождает от административной ответственности за данное правонарушение юридическое лицо.

В соответствии с Федеральным законом от 05.04.2013 N 44-Ф3 «0 контрактной системе в сфере закупок товаров, работ, услуг для обеспечения государственных и муниципальных нужд» (далее 44-Ф3) согласно статье 3 определяются основные понятия, используемые в сфере осуществления контроля в отношении контрактов в сфере государственного оборонного заказа. В частности, понятие «контрольный орган в сфере закупок согласно п. 13 указанной статьи означает»...федеральный орган исполнительной власти, орган исполнительной власти субъекта Российской Федерации, орган местного самоуправления муниципального района, орган местного самоуправления городского округа, уполномоченные на осуществление контроля в сфере закупок, а также федеральный орган исполнительной власти, уполномоченный на осуществление функций по контролю (надзору) в сфере государственного оборонного заказа (далее ГО3) и в сфере закупок товаров, работ, услуг для обеспечения федеральных нужд, которые не относятся к государственному оборонному заказу и сведения о которых составляют государственную тайну». Таким образом, можно сделать вывод, что отечественный законодатель (причем в большинстве случаев) не устанавливает принципиальных различий между понятиями «контроль» и «надзор» $[2]$.

Функция надзора заключается в постоянном, систематическом наблюдении специальных государственных органов за деятельностью не подчиненных им органов или лиц с целью выявления нарушений законности. При этом оценка деятельности поднадзорного объекта дается только с точки зрения законности, но не целесообразности.

Глава 5 44-Ф3, посвящена осуществлению контрольной деятельности в этой сфере. Прежде всего, указанный закон, помимо государственного финансового контроля, вводит еще 3 вида: ведомственный, общественный и контроль, осуществляемый заказчиком.

В связи с упразднением в 2014 году Федеральной службы по гособоронзаказу с передачей ее функций в части контроля за ценами и торгами Федеральной антимонопольной службе (ФАС), а контрольно-аналитических - Счетной палате РФ были приняты изменения в Федеральный закон от
29.06.2015 N 159-Ф3 «0 внесении изменений в Федеральный закон «О государственном оборонном заказе» и отдельные законодательные акты Российской Федерации»,который должен повысить эффективность контроля использования бюджетных средств при исполнении государственного оборонного заказа (далее ГО3), предотвратить необоснованное завышение стоимости ГО3, а также регламентировать порядок проведения ФАС проверок, возбуждения, рассмотрения и обжалования дел о нарушении Закона о ГОЗ[3].

Осуществление указанных изменений было осуществлено в целях совершенствования государственного управления и контроля в сфере государственного оборонного заказа вооружения, военной, специальной техники и материальных средств. Ведомственный контроль в сфере ГОЗ был передан Министерству внутренних дел Российской Федерации, Министерству Российской Федерации по делам гражданской обороны, чрезвычайным ситуациям и ликвидации последствий стихийных бедствий, Министерству обороны Российской Федерации, Службе внешней разведки Российской Федерации, Федеральной службе безопасности Российской Федерации, Федеральной службе Российской Федерации по контролю за оборотом наркотиков, Федеральной службе охраны Российской Федерации и Федеральной службе исполнения наказаний функции упраздняемого Федерального агентства по поставкам вооружения, военной, специальной техники и материальных средств в области размещения заказов, заключения, оплаты, контроля и учета выполнения государственных контрактов по государственному оборонному заказу по всей номенклатуре вооружения, военной, специальной техники и материальных средств. Статья 23.82 КоАП РФ устанавливает осуществление функций контроля федеральным органом исполнительной власти, осуществляющего функции по контролю и надзору в сфере ГОЗ путем рассмотрения дела об административных правонарушениях, предусмотренных частью 3 статьи7.29, статьями 7.29.1, 7.29.2, частью 15 статьи 7.30, статьей 7.32.1, частью 11 статьи 9.16 (в части государственного оборонного заказа и государственной тайны), частями 1 и 2 статьи 14.43, статьями 14.44, 14.49, частями 1 и 2 статьи 14.55, статьей 15.37, частью 7.1 статьи 19.5, статьей 19.7.2 (в части государственного оборонного заказа и государственной тайны) КоАП РФ.

Предметом регулирования ведомственного контроля является проверка соблюдения законодательства Российской Федерации в сфере государственного оборонного заказа государственными заказчиками, головными исполнителями, исполнителями, федеральными органами испол- 
нительной власти, иными осуществляющими в установленном порядке функции указанных органов органами или организациями, а также их должностными лицами (далее - проверяемое лицо), в том числе проверка:

- соблюдения порядка ценообразования на продукцию, поставляемую по государственному оборонному заказу, формирования и применения государственных регулируемых цен на такую продукцию при размещении и выполнении государственного оборонного заказа;

- обоснованности заключения государственных контрактов (контрактов, договоров) по государственному оборонному заказу и соблюдения условий их выполнения, в том числе в части приемки и оплаты товаров, выполнения работ, оказания услуг;

- $\quad$ исполнения государственных контрактов в сфере государственного оборонного заказа в пределах компетенции контролирующего органа;

- надлежащего использования бюджетных ассигнований, выделяемых из федерального бюджета на выполнение государственного оборонного заказа и надлежащего выполнения финансовых обязательств по заключенным государственным контрактам (договорам)[4].

Хотя контроль осуществляется еще непродолжительное время, но уже появились полезные наработки. Контроль может осуществляться на этапе публикации извещения на официальном сайте до момента заключения контракта, когда в случае выявления нарушения требований законодательства может быть выдано предписание об их устранении. После того, как контракт заключен выдать предписания уже становиться невозможным, однако, можно привлечь к административной ответственности либо обратиться с иском в суд о расторжении контракта. Но это все после заключения и начала исполнения контакта достаточно сложно.

Что касается сферы ГОЗ, то контроль затрагивает весь цикл: планирование, определение поставщика и исполнение контракта. Контроль осуществляется в ходе внеплановых проверок по закону 44-ФЗ и по 275-ФЗ.

Контроль делится на несколько направлений: - $\quad$ Со стороны процедуры (44-Ф3).

- Непосредственно в сфере закупок, то есть связанный со спецификой государственного оборонного заказа.

Деятельность по заключению контрактов в сфере ГОЗ регламентируется не только Федеральным законом от 05.04.2013 № 44-Ф3 «О контрактной системе в сфере закупок товаров, работ, услуг для обеспечения государственных и муниципальных нужд». Большую роль играет 275-ФЗ
«0 государственном оборонном заказе», который касается не только обязанностей поставщиков и заказчиков, но и особенностей контроля, в котором прописал четкий порядок всех процедур. Кроме того, указанная деятельность регламентируется Постановлениями Правительства РФ от 26.12.2013 № 1255 «О правилах разработки ГОЗ и его основных показателей», от 28.04.2015 № 407 «0 порядке определения начальной (максимальной) цены государственного контракта, а также цены государственного контракта, заключаемого с единственным поставщиком (подрядчиком, исполнителем), при осуществлении закупок товаров, работ, услуг по гособоронзаказу», от 24.12.2013 № 1224 «Об установлении запрета и ограничений на допуск товаров, происходящих из иностранных государств, работ (услуг), выполняемых (оказываемых) иностранными лицами, для целей осуществления закупок товаров, работ (услуг) для нужд обороны страны и безопасности государства».

Законом 275-ФЗ установлено ограничение, которое касается того, что в закупках могут участвовать только юридические лица. Соответственно, индивидуальный предприниматель не является юридическим лицом. Заявка любого физического лица, в том числе и индивидуального предпринимателя, будет отклонена. Дополнительные ограничения на допуск к торгам являются преференции к отечественным производителям. Если товар закупается в рамках оборонного заказа, то параллельно используется преференция. Допускается товар только отечественного производства, но существуют и преференции к иностранным производителям [5].

Особо следует выделить осуществление контроля согласования контракта с единственным поставщиком. Это связано с тем, что заказы в сфере обороны специфические и поставщиков не так много. В сфере государственного оборонного заказа существует и контроль заключения контракта с единственным поставщиком. Еще одно направление контроля - ведение реестра недобросовестных поставщиков.

Глава 5.1 № 275-Ф3 определяет функции контролирующего органа. Контролирующий орган выполняет следующие основные функции:

1) осуществляет в пределах своей компетенции государственный контроль (надзор) за соблюдением законодательства в сфере государственного оборонного заказа, за исключением осуществления государственного контроля (надзора) в отношении государственных контрактов в сфере закупок товаров, работ, услуг в целях обеспечения органов внешней разведки Российской Федерации средствами разведывательной деятельности, в целях обеспечения 
органов федеральной службы безопасности средствами контрразведывательной деятельности, борьбы с терроризмом, а также в целях обеспечения Государственной корпорации по атомной энергии «Росатом» товарами, работами, услугами по разработке, испытаниям, производству, разборке и утилизации ядерных боеприпасов и ядерных зарядов, обеспечению их надежности и безопасности на всех стадиях жизненного цикла, поддержанию базовых и критических технологий на всех стадиях жизненного цикла ядерных боеприпасов, ядерных зарядов, в том числе обеспечению ядерной и радиационной безопасности, формированию государственного запаса специального сырья и делящихся материалов;

2) выявляет нарушения законодательства в сфере государственного оборонного заказа, принимает меры по их прекращению и привлекает к ответственности за такие нарушения;

3) принимает меры по предупреждению нарушений законодательства в сфере государственного оборонного заказа;

4) обеспечивает защиту публичных интересов Российской Федерации при осуществлении государственного контроля (надзора) в сфере государственного оборонного заказа.

При выявлении в ходе проверок признаков административных правонарушений согласно статье 15.2 275-ФЗ контролирующий орган

- $\quad$ возбуждает и рассматривает дела о нарушениях законодательства в сфере государственного оборонного заказа;

- привлекает к административной ответственности за нарушение законодательства в сфере государственного оборонного заказа;

- обращается в суд с исками и заявлениями о нарушении законодательства в сфере государственного оборонного заказа;

- осуществляет в пределах своей компетенции в соответствии с законодательством Российской Федерации производство по делам об административных правонарушениях;

С целью осуществления указанных полномочий в соответствии со статьей 15.3 N 275-Ф3 контролирующий орган вправе запрашивать у государственных заказчиков, исполнителей, головных исполнителей в установленный срок по мотивированному требованию необходимые документы, объяснения, информацию соответственно в письменной и устной форме (в том числе содержащую сведения, составляющие государственную, налоговую, банковскую, служебную, коммерческую и иную охраняемую законом тайну, а также персональные данные), включая акты, договоры, справки, деловую корреспонденцию, иные документы и материалы, выполненные в форме цифровой записи или в форме записи на электронных носителях.

В случае выявления признаков нарушения законодательства в сфере оборонного заказа, то производство по таки делам осуществляется в особом, специальном порядке, предусмотренным главой 5.2. № 275-Ф3.

Контролирующий орган при выявлении признаков нарушения части 3 статьи 8 № 275-Ф3 возбуждает и рассматривает дела о нарушении законодательства в сфере государственного оборонного заказа. Возбуждение дела об административном правонарушении осуществляется в общем порядке, установленном законодательством Российской Федерации [6- Ст. 15.11]

Основаниями для возбуждения дела о нарушении законодательства в сфере государственного оборонного заказа является информация о наличии признаков административного правонарушения, поступившая либо от третьих лиц, например, в сообщениях СМИ либо обнаруженные в ходе осуществления проверки [7-ст.15.12]

Статья 15.17. N 275-Ф3 устанавливает порядок рассмотрения заявлений, материалов и возбуждения дела о нарушении законодательства в сфере государственного оборонного заказа. Если основанием явились заявления или поступившие материалы, то контролирующий орган рассматривает заявление, материалы в течение тридцати календарных дней со дня их поступления.

По результатам рассмотрения заявления, материалов контролирующий орган принимает одно из следующих решений:

1) о возбуждении дела о нарушении законодательства в сфере государственного оборонного заказа;

2) об отказе в возбуждении дела о нарушении законодательства в сфере государственного оборонного заказа.

В случае принятия решения о возбуждении дела о нарушении законодательства в сфере государственного оборонного заказа контролирующий орган издает приказ о возбуждении дела о нарушении законодательства в сфере государственного оборонного заказа и создании комиссии. Копии такого приказа в течение трех дней со дня его издания направляются заявителю и ответчику по делу.

В течение пятнадцати дней со дня издания приказа о возбуждении дела о нарушении законодательства в сфере государственного оборонного заказа и создании комиссии, председатель комиссии выносит определение о назначении дела к рассмотрению и направляет копии определения лицам, участвующим в деле.

Территориальная подведомственность определяется, в отличие от общего порядка, предус- 
мотренного ст. 29.5 КоАП РФ, контролирующим органом вне зависимости от места совершения нарушения, места нахождения либо места жительства лица, в отношении которого подано заявление или поступили материалы.

Для рассмотрения создается особый орган комиссия по рассмотрению дела о нарушении законодательства в сфере государственного оборонного заказа (далее - комиссия). Комиссия состоит из должностных лиц контролирующего органа. Количество членов комиссии не должно быть менее чем три человека. Комиссия правомочна рассматривать дело о нарушении законодательства в сфере государственного оборонного заказа, если на заседании комиссии присутствует не менее чем пятьдесят процентов общего числа членов комиссии, но не менее чем три члена комиссии.

Вопросы, возникающие в ходе рассмотрения комиссией дела о нарушении законодательства в сфере государственного оборонного заказа, решаются членами комиссии большинством голосов. При равенстве голосов голос председателя комиссии является решающим. Члены комиссии не вправе воздерживаться от голосования. Председатель комиссии голосует последним.

По окончании рассмотрения дела о нарушении законодательства в сфере государственного оборонного заказа комиссия на своем заседании принимает решения, выдает предписания, выносит определения [8-ст.15.13].

Дело о нарушении законодательства в сфере государственного оборонного заказа не может быть возбуждено, а возбужденное дело подлежит прекращению по истечении трех лет со дня совершения нарушения. При длящемся нарушении законодательства в сфере государственного оборонного заказа срок давности исчисляется со дня окончания нарушения или его обнаружения. Указанный срок отличается от срока, определенного статьей 4.5 КоАП РФ, которая устанавливает сроки давности привлечения к административной ответственности: не позднее двух месяцев (по делу об административном правонарушении, рассматриваемому судьей, - по истечении трех месяцев) со дня совершения административного правонарушения, за нарушение законодательства Российской Федерации в сфере государственного оборонного заказа (в части административных правонарушений, предусмотренных статьей 7.32.1 КоАП РФ), о контрактной системе в сфере закупок товаров, работ, услуг для обеспечения государственных и муниципальных нужд (в части административных правонарушений, предусмотренных статьями 7.29 - 7.32, частью 7 статьи 19.5, статьей 19.7.2 КоАП РФ), законодательства Российской Федерации в сфере закупок товаров, работ, услуг отдельными видами юридических лиц (в части административных правонарушений, предусмотренных статьей 7.32.3, частью 7.2 статьи 19.5, статьей 19.7.2-1 КоАП РФ).

Само рассмотрение дела о нарушении законодательства в сфере государственного оборонного заказа должно быть осуществлено комиссией в срок, не превышающий девяноста календарных дней со дня вынесения определения о назначении дела к рассмотрению. В случае необходимости получения дополнительной информации, а также в иных случаях, предусмотренных настоящей главой, срок рассмотрения дела может быть продлен комиссией, но не более чем на сто восемьдесят календарных дней. 0 продлении срока рассмотрения дела комиссия выносит определение, копии которого направляются лицам, участвующим в деле [9-ст.15.18].

Сроки рассмотрения дела об административном правонарушении в сфере ГОЗ различаются в зависимости от того органа, который это дело рассматривает. В соответствии со статьей 29.6 № 275-ФЗ дело об административном правонарушении рассматривается в пятнадцатидневный срок со дня получения органом, должностным лицом, правомочными рассматривать дело, протокола об административном правонарушении и других материалов дела либо материалов, полученных с применением работающих в автоматическом режиме специальных технических средств, имеющих функции фото- и киносъемки, видеозаписи, или средств фото- и киносъемки, видеозаписи. Если дело рассматривается судьей, то оно рассматривается в двухмесячный срок со дня получения судьей, правомочным рассматривать дело, протокола об административном правонарушении и других материалов дела.

При рассмотрении дела об административном правонарушении в сфере ГОЗ комиссия в рамках общего решения разрешает вопросы о выдаче и содержании предписаний, а также о необходимости осуществления других действий, направленных на устранение и (или) предотвращение нарушения законодательства в сфере государственного оборонного заказа, в том числе о направлении материалов в правоохранительные органы, об обращении в суд, о направлении предложений и рекомендаций в государственные органы.

Указанные предписания согласно статья 15.25 № 275-Ф3 подлежат исполнению в срок, установленный в предписании. Контроль за исполнением предписания осуществляет контролирующий орган. Неисполнение в срок предписания (т.е уклонение от исполнения предписания или частичное его исполнение в установленный в предписании срок.) по делу о нарушении законодательства в сфере го- 
сударственного оборонного заказа влечет за собой административную ответственность, т.к. является нарушением законодательства в сфере государственного оборонного заказа [10-ст.19.5].

Принятое решение может быть обжаловано, однако, обжалование предписания не исключает обязанность его исполнения.

Указанный порядок осуществления ведомственного контроля установлен в целях увеличения эффективности и результативности осуществления закупок, а также недопущения злоупотреблений при осуществлении закупок для обеспечения государственных и муниципальных нужд.

Осуществление ведомственного контроля призвано минимизировать риски участников ГОЗ, дисциплинировать их в отношениях, связанных с осуществлением порядка заключения контрактов в сфере Г03, а также осуществления своих обязательств. В целом, установление административной ответственности в сфере ГОЗ является одним из эффективных способов предупреждения и пресечения нарушений в области государственного оборонного заказа.

\section{Библиография:}

1. Федеральный закон от 26.12.2008 N 294-Ф3 "О защите прав юридических лиц и индивидуальных предпринимателей при осуществлении государственного контроля (надзора) и муниципального контроля" // Собрание законодательства Российской Федерации. 2008. N 52 (ч. I). Ст. 6249.

2. Федеральный закон от 29.12.2012 N 275-Ф3 (ред. от 13.07.2015) "О государственном оборонном заказе" ст. 15.18. N 275-ФЗ//СПС КонсультантПлюс.

3. Федеральный закон от 05.04.2013 N 44-Ф3 "О контрактной системе в сфере закупок товаров, работ, услуг для обеспечения государственных и муниципальных нужд".

4. Указ Президента РФ от 08.09.2014 N 613 "О некоторых вопросах государственного управления и контроля в сфере государственного оборонного заказа вооружения, военной, специальной техники и материальных средств" // СПС КонсультантПлюс.

5. Башлаков И.Н. Антимонопольный контроль в сфере государственного оборонного заказа//http://dfnc.ru/ oboronzakaz

6. Кривоносов А.Н. К вопросу о понятии административного правонарушения // Административное и муниципальное право. 2010. № 4. С. 66-69.

7. Никитина Е.В. Закупки в сфере государственного оборонного заказа /http://www.otc.ru

8. Серов А.С. Административно-процессуальная правосубъектность участников производства по делам об административных правонарушениях // Административное и муниципальное право. 2014. № 2. С. 158-164.

9. Слепенкова Л.В. Административные правонарушения в области государственного оборонного заказа / Л.В. Слепенкова // Административное право и процесс. 2009. № 6. С. 76.

10. Васильев Р.И. Государственный контроль как функция управления. // Полицейская деятельность. - 2011. - 2. С. $65-71$.

11. Яворская М.В. Сильные и слабые стороны российской системы государственных закупок и ее значение для защиты интересов отечественного бизнеса и производства // Финансы и управление. - 2013. - 3. - C. 37 - 52. DOI: 10.7256/2409-7802.2013.3.9592. URL: http://www.e-notabene.ru/flc/article_9592.html

\section{References (transliterated):}

1. $\quad$ Federal'nyi zakon ot 26.12.2008 N 294-FZ "O zashchite prav yuridicheskikh lits i individual'nykh predprinimatelei pri osushchestvlenii gosudarstvennogo kontrolya (nadzora) i munitsipal'nogo kontrolya" // Sobranie zakonodatel'stva Rossiiskoi Federatsii. 2008. N 52 (ch. I). St. 6249.

2. Federal'nyi zakon ot 29.12.2012 N 275-FZ (red. ot 13.07.2015) "O gosudarstvennom oboronnom zakaze" st. 15.18. N 275FZ//SPS Konsul'tantPlyus.

3. Federal'nyi zakon ot 05.04.2013 N 44-FZ "O kontraktnoi sisteme v sfere zakupok tovarov, rabot, uslug dlya obespecheniya gosudarstvennykh i munitsipal'nykh nuzhd".

4. Ukaz Prezidenta RF ot 08.09.2014 N 613 "O nekotorykh voprosakh gosudarstvennogo upravleniya i kontrolya v sfere gosudarstvennogo oboronnogo zakaza vooruzheniya, voennoi, spetsial'noi tekhniki i material'nykh sredstv" // SPS Konsul'tantPlyus.

5. Bashlakov I.N. Antimonopol'nyi kontrol' v sfere gosudarstvennogo oboronnogo zakaza//http://dfnc.ru/oboronzakaz

6. Krivonosov A.N. K voprosu o ponyatii administrativnogo pravonarusheniya // Administrativnoe i munitsipal'noe pravo. 2010. № 4. S. 66-69.

7. Nikitina E.V. Zakupki v sfere gosudarstvennogo oboronnogo zakaza /http://www.otc.ru

8. Serov A.S. Administrativno-protsessual'naya pravosub"ektnost' uchastnikov proizvodstva po delam ob administrativnykh pravonarusheniyakh // Administrativnoe i munitsipal'noe pravo. 2014. № 2. S. 158-164.

9. Slepenkova L.V. Administrativnye pravonarusheniya v oblasti gosudarstvennogo oboronnogo zakaza / L.V. Slepenkova // Administrativnoe pravo i protsess. 2009. № 6. S. 76.

10. Vasil'ev R.I. Gosudarstvennyi kontrol' kak funktsiya upravleniya. // Politseiskaya deyatel'nost'. - 2011. - 2. - C. 65 - 71.

11. Yavorskaya M.V. Sil'nye i slabye storony rossiiskoi sistemy gosudarstvennykh zakupok i ee znachenie dlya zashchity interesov otechestvennogo biznesa i proizvodstva // Finansy i upravlenie. - 2013. - 3. - C. 37 - 52. DOI: 10.7256/24097802.2013.3.9592. URL: http://www.e-notabene.ru/flc/article_9592.html 